\title{
A Política no Paraná com a participação de Imigrantes e descendentes de Poloneses
}

\author{
Rafaela Mascarenhas Rocha ${ }^{1}$
}

Resumo: Com a alta produção de erva mate no Paraná a partir da segunda metade do século XIX, surgiu uma crise de abastecimento de alimentos e a necessidade de ocupação de terras devolutas. A solução encontrada pela elite local foi incentivar a vinda de imigrantes europeus, que cultivassem a terra com alimentos para abastecer as cidades. Este trabalho é dedicado a falar do grupo de imigrantes poloneses que veio ao Paraná. O país do leste europeu fora dominado por três impérios durante os séculos XVIII e XIX: Prússia, Áustria e Rússia, e com extrema miséria, fome, doenças e guerras, portanto, a solução de grande parte da população polonesa durante o século XIX foi emigrar. Os poloneses começaram a chegar ao Brasil em 1869, e ao Paraná em 1871, ocupando colônias rurais nos arredores das cidades, e foi este o grupo imigrante mais numeroso no Paraná, conforme Oliveira (2010) chegando a mais de 41 mil imigrantes no Paraná entre 1870 e 1914. Muitos descendentes de poloneses não ficaram no trabalho agrícola, mas se ocuparam da política em Curitiba e em cidades vizinhas, permitindo assim, pensar em uma ação unificada em favor dos interesses e demandas deste grupo de imigrantes e descendentes.

Palavras-Chave: Imigrantes, Poloneses, Paraná.

\section{The Politics in Paraná with the participation of Immigrants and descendants of Poles}

\begin{abstract}
With the higher production of mate grass in Paraná in the second half of the nineteenth century, a crisis of food supply and the need to occupy vacant lands arose. The solution founded by the local elite was to encourage the arrival of European immigrants, who cultivated the land with food to supply the cities. This work is dedicated to speaking of the group of Polish immigrants who came to Paraná. The eastern European country was dominated by three empires during the eighteenth and nineteenth centuries: Prussia, Austria and Russia, and with extreme poverty, hunger, disease and war, so the solution of much of the Polish population during the nineteenth century was to emigrate. The Polish began to arrive in Brazil in 1869, and to Paraná in 1871, occupying rural colonies in the outskirts of the cities, and this was the largest immigrant group in Paraná, according to Oliveira (2010) reaching more than 41,000 immigrants in Paraná between 1870 and 1914. Many descendants of Polish did not stay in the agricultural work, but took care of the politics in Curitiba and in neighboring cities, thus, to think of a unified action in favor of the interests and demands of this group of immigrants and descendants.
\end{abstract}

Key words: Immigrants, Polish, Paraná.

*Recebido em 30/05/2018.

* Aceito em 10/06/2018.

\footnotetext{
${ }^{1}$ Doutoranda em Sociologia pelo Programa de Pós-graduação em Sociologia, da UFPR. Agência Financiadora CAPES, e-mail: rafaela_mrocha@yahoo.com.br.
} 


\section{Introdução}

Este artigo se constitui em uma atualização científica de um trabalho anterior, feito a convite do Núcleo de Estudos Paranaenses (NEP) da UFPR, que tratou a respeito da influência dos imigrantes e descendentes de poloneses na política e na vida pública em geral, no estado do Paraná, especialmente na região metropolitana de Curitiba e sul do estado. Inicialmente apresentamos um histórico da imigração polonesa ao Paraná, com as razões que motivaram o governo local para atrair as famílias estrangeiras da Europa para cá e as localidades onde foram estabelecidas as chamadas colônias aos imigrantes, usualmente localizadas nos arredores do território de Curitiba, pois contava com um melhor aparato de estradas e vias, para uma razoável comunicação dos imigrantes com a cidade e também facilitando o escoamento da produção agrícola das colônias. Após este histórico, o texto passa a descrever algumas biografias de imigrantes ou descendentes de poloneses que estiveram envolvidos na política local e também na vida pública paranaense, exercendo cargos públicos técnicos, por indicação ou eletivos, desde as primeiras décadas do século XX, em várias regiões do estado.

\section{A chegada dos imigrantes poloneses à região de Curitiba}

Entre os séculos XVIII e XIX, a economia paranaense esteve voltada para a produção de bens para comércio com outras regiões, ou outros países. Tanto a pecuária, estendendo-se ao comércio de gado com os tropeiros, quanto a exportação de erva mate para países vizinhos, e a atividade madeireira garantiram a economia local, (IANNI, 1988). Porém, após a Emancipação Política, em 1853, os governantes paranaenses notaram uma considerável escassez de alimentos nas cidades, tornando, portanto, necessária a ampliação da economia local para a via agrícola, indo além da produção de subsistência. Foi então que o incentivo à imigração de famílias europeias e a instalação destas em áreas rurais - consideradas devolutas e que ficavam próximas às cidades - surgiu como uma solução viável par ao aumento da produção de alimentos. Além do trabalho com a agricultura, os imigrantes seriam também direcionados a trabalhos em obras de infraestrutura: como construção de estradas para melhor escoar produção de erva mate, para projetar a economia paranaense para uma das principais e mais lucrativas do país, saindo da condição de subsistência na qual se encontrara. 
Para instalação dos imigrantes europeus que chegavam, o poder público organizou colônias rurais, áreas destinadas exclusivamente aos imigrantes, cuja divisão era feita para cada família. Fazia também a administração e a distribuição do espaço: denominando-os e construindo edificações que abrigassem as instituições primordiais para a vida dos imigrantes, como igrejas e escolas. O referido poder público trata-se da prefeitura municipal - em especial no caso da capital, Curitiba - o governo provincial do Paraná, ou o governo imperial. A instalação de colônias mais próximas do centro de Curitiba foi feita pelo município; aquelas localizadas nos arredores da área urbana foram de iniciativa provincial; e as colônias fundadas pelo Império eram as mais distantes nos núcleos urbanos (KANASHIRO, 2006).

O grupo de imigrantes poloneses que veio ao Paraná - a partir do ano de 1871 - era heterogêneo quanto ao ramo de atividades profissionais, contudo possuíam certa familiaridade com o modelo de produção em agricultura familiar das colônias, por ser semelhante ao que já tinham na Europa (BOSCHILIA, 2004). Nos arredores da capital paranaense foram fundadas quatro colônias exclusivas para os imigrantes poloneses e uma colônia mista que também recebeu imigrantes poloneses, entre outros grupos e que passam a serem apresentadas aqui em ordem cronológica quanto à data de suas fundações:

\section{a) A Colônia Pilarzinho}

Pilarzinho foi a primeira colônia para imigrantes fundada em Curitiba, em 1870. Uma colônia mista criada com o intuito de receber soldados que retornavam da guerra do Paraguai e que recebera imigrantes alemães e em seguida famílias de poloneses transmigrados de colônias catarinenses, também a ocuparam. Pilarzinho foi uma colônia construída por iniciativa municipal, localizada na região norte de Curitiba, a 4 km do centro da cidade (ROCHA, 2016).

\section{b) A Colônia Abranches}

Três anos após a inauguração de Pilarzinho, em 1873, o município de Curitiba, cria a primeira colônia exclusiva para imigrantes poloneses, era o Abranches. Distante a 6 km do centro da cidade, a colônia - a colônia homenageia o então presidente da Província do Paraná, Francisco de Araújo Abranches - era habitada por 320 famílias polonesas distribuídas em 82 lotes, onde viviam imigrantes poloneses da região da Silésia (WACHOWICZ, 1976). 
c) A Colônia Orleans

Em 1875, o governo provincial inaugura a Colônia Orleans, localizada próxima ao Rio Barigui e às margens da estrada para o Mato Grosso, na região oeste de Curitiba e a $10 \mathrm{~km}$ do centro da cidade. A colônia foi dividida em 66 lotes e recebeu 63 famílias, na sua fase inicial. Lá foi instalada a primeira escola em uma colônia de imigrantes, em 1876, construída por iniciativa dos imigrantes e que teve o primeiro professor o polono-brasileiro Jerônimo Durski, que lecionava em polonês (OLIVEIRA, 2010).

d) A Colônia de Santa Cândida

Também em 1875, a província do Paraná compra uma área de um proprietário brasileiro, às margens da Estrada da Graciosa e cria a colônia Santa Cândida, localizada a $8 \mathrm{~km}$ a norte do centro da cidade. Dividida em 40 lotes, sua ocupação inicial foi de 168 habitantes segundo o Boletim Casa Romário Martins (1975). Tanto Orleans, quanto Santa Cândida receberam a ilustre visita do Imperador Dom Pedro II em 1880.

e) A Colônia de Santo Inácio

Em 1876 a Província do Paraná cria a Colônia de Santo Inácio, vizinha a Orleans. Inicialmente, Santo Inácio recebeu 514 habitantes, também provenientes da região da Silésia, como a maioria dos poloneses que vieram a Curitiba (BOSCHILIA, 2004).

Entre a população descendente de polonês em Curitiba, não há uma regra geral que os condicionem a serem pessoas de origem camponesa, que se mantiveram nas áreas rurais da cidade e na lida com a terra; existiram e existem, sim, personagens que trabalharam fora do espaço rural, com empreendimentos, comunicação, educação, comércios, serviços, entre outros ofícios. E alcançaram destaque entre a sociedade local e prestígio em importantes espaços políticos. A seguir, será mostrado como alguns imigrantes poloneses chegaram a ocupar postos de destaque no poder público local, apresentando parte da trajetória destes indivíduos ao contar quais os postos por eles ocupados e o trabalho exercido, em que épocas isso se deu e quem eram estas pessoas. Antes, porém, apresentam-se mais colônias polonesas, agora as que existiram em outras cidades do Paraná.

As colônias polonesas na região oeste de Curitiba fizeram parte do Distrito Administrativo de Nova Polônia, com projeto assinado pela Câmara Municipal em agosto de 
1892. Este distrito funcionou por 46 anos - de 1892 até 1938 - quando o Decreto-Lei estadual 7.573 de 20 de outubro de 1938, revogou sua criação. O Distrito de Nova Polônia reunia as colônias polonesas próximas à antiga estrada do Mato Grosso, na parte oeste da capital ${ }^{2}$ e foi concebida com o propósito de organizar a administração municipal nesta região (WACHOWICZ, 1976).

A maioria das colônias que receberam imigrantes poloneses em Curitiba mantiveram as mesmas dimensões territoriais e localizações, mantiveram também os mesmos nomes da época em que eram apenas colônias, quando se tornaram bairros da capital, sendo a exceção a colônia Dom Augusto, que ao se tornar bairro passou a se chamar Augusta. Essa fidelidade pode ser percebida nos mapas a seguir:

\footnotetext{
${ }^{2}$ As Colônias a oeste da área urbana de Curitiba eram Orleans, S. Inácio, Rivière, D. Pedro, D. Augusto e Tomás Coelho - todas fundadas durante o período do Presidente Provincial Lamenha Lins.
} 
Mapa 1: A cidade de Curitiba entre os anos de 1947 - 1953.

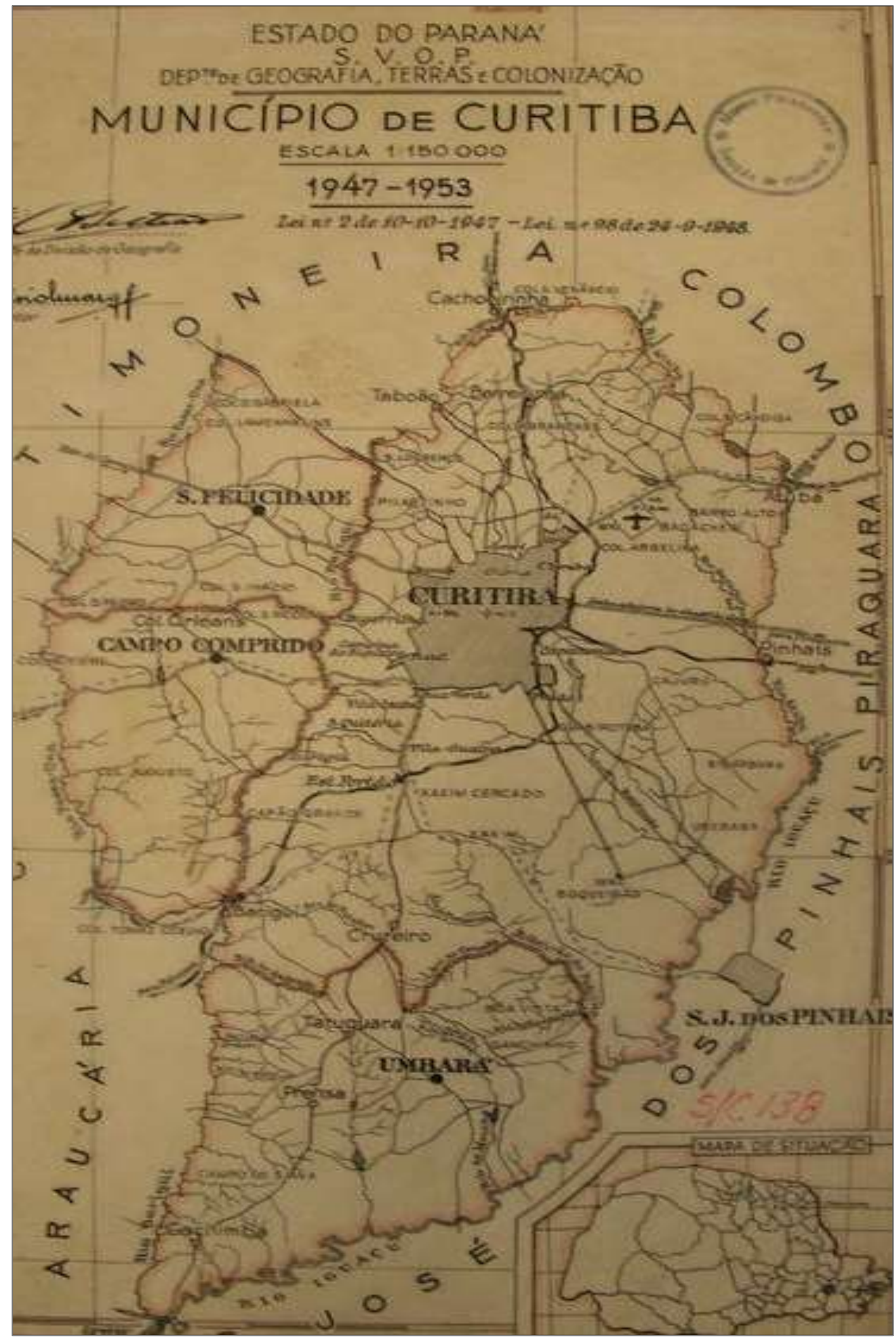


Fonte: www.museuparanaense.pr.gov.br

Nota-se, neste primeiro mapa, que nesse antigo mapeamento da área da capital datado da primeira metade do século XX, as áreas ocupadas pelos imigrantes colônias ainda estão descritas como colônias, e não como bairros, no entanto, elas possuem os nomes pelos quais são conhecidas até os dias atuais. No mapa 1, é possível verificar as colônias Orleans e Santo Inácio na parte oeste da cidade, próximo ao Campo Comprido. Há também a colônia Santa Cândida, ao noroeste da cidade, próximo do limite com Colombo e a Colônia Abranches ao norte. Mesmo que este mapa seja das décadas de 1940 e 1950, a utilização da terminologia "colônia" para estas localidades pode indicar que o crescimento da cidade ainda não havia possibilitado o avanço da urbanização até essas regiões, demonstrando o predomínio das características iniciais, dos tempos da imigração, ou seja, que ainda eram redutos rurais da cidade com população de maioria imigrante. Outro destaque do Mapa 1 é a presença da colônia Dom Pedro como sendo parte da capital, área esta que atualmente pertence ao município vizinho de Campo Largo.

A seguir, apresenta-se um mapa contemporâneo da capital paranaense, que possibilita ao leitor verificar a localização atual das antigas colônias polonesas em Curitiba, e os bairros que elas se tornaram. O Mapa 2 pode ser comparado ao primeiro, se observada a fidelidade das antigas áreas coloniais em relação aos bairros urbanos que estas se tornaram com a modernização e completa urbanização da cidade, os nomes e as áreas delimitadas permaneceram praticamente as mesmas. 
Mapa 2: Mapeamento atual da cidade de Curitiba, com as delimitações dos bairros e o destaque para aqueles que foram colônias polonesas no pasado.

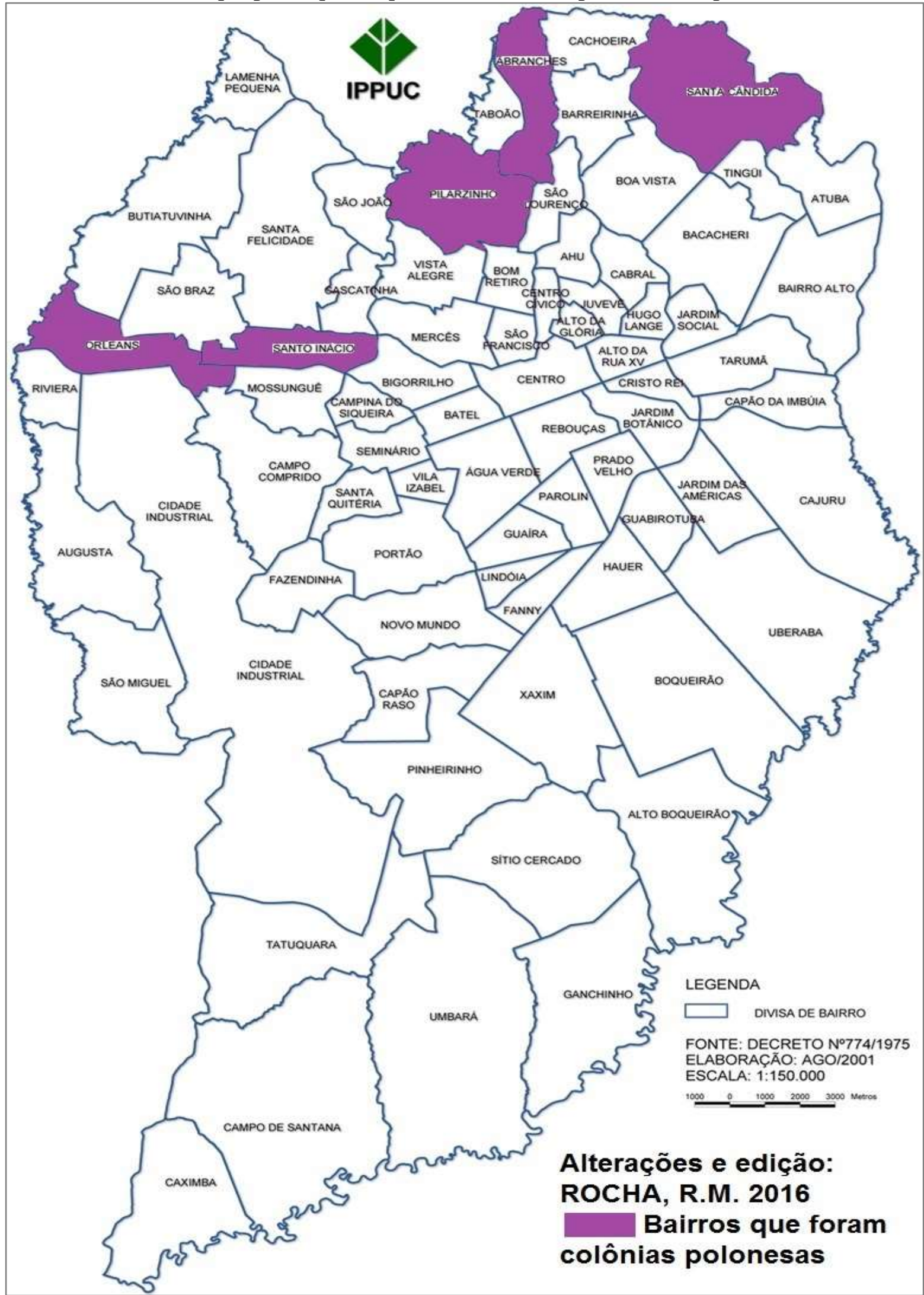

Fonte: www.ippuc.org.br. Alterações: ROCHA, R.M., 2017. 
Observando o Mapa 2, nota-se também, que são bairros bastante próximos entre si: se pode ver que mesmo a colônia mista de Pilarzinho - a primeira a ser inaugurada em 1870 - está logo ao lado da colônia polonesa do Abranches; as ex-colônias Orleans e Santo Inácio são vizinhas uma da outra e também da ex-colônia italiana de Santa Felicidade, que também manteve o nome de colônia e é muito movimentado pelo turismo gastronômico.

Sobre a população descendente de polonês em Curitiba, apesar de ter existido uma literatura dominante que por muitos anos deu conta de que esse grupo estivera condicionado a serem pessoas de origem camponesa pobre e que se mantiveram nas áreas rurais da cidade e na lida com a terra, este conceito sofreu atualizações dentro da perspectiva histórica e sociológica acerca dos estudos deste grupo como em Oliveira (2010) e muitos outros trabalhos. Existiram e existem, sim, personagens que trabalharam fora do espaço rural, com empreendimentos, comunicação, educação, comércios, serviços, entre outros ofícios. E alcançaram destaque entre a sociedade local e prestígio em importantes espaços políticos.

A seguir, será mostrado como alguns imigrantes poloneses chegaram a ocupar postos de destaque no poder público local, apresentando parte da trajetória destes indivíduos ao contar quais os postos por eles ocupados e o trabalho exercido, em que épocas isso se deu e quem eram estas pessoas. Antes, porém, apresentam-se mais regiões de imigração polonesa e outras colônias que existiram em outras cidades do Paraná.

\section{Imigrantes poloneses para além da capital}

Muitas das colônias polonesas construídas na segunda metade do século XIX eram no município de Curitiba e foram desmembradas ao longo do tempo, passando a fazer parte dos municípios vizinhos à capital. Isso aconteceu, entre outros casos, com a colônia Tomás Coelho ${ }^{3}$ que fundada em 1876 conforme dito acima, através de iniciativa provincial, quando o Paraná estava sob a presidência de Lamenha Lins (KANASHIRO, 2006). Mais distante da cidade, Tomás Coelho ficava nas proximidades da estrada para a Lapa - a $16 \mathrm{~km}$ do centro de Curitiba - já pertenceu a Curitiba e se desmembrou, ficando parte em Campo Largo - vindo a se tornar

\footnotetext{
${ }^{3}$ Ora escrito Tomaz Coelho, com z e sem acento, pelos pesquisadores.
} 
o bairro Ferraria - e parte em Araucária, em um bairro que não leva mais este nome, e que teve uma parte alagada pela represa do Passaúna (OBRZUT, 2006).

Outra importante colônia de imigrantes da região leste do Paraná era a Colônia Dom Pedro, também fundada em 1876. Muito próxima à Colônia Orleans, Dom Pedro atualmente faz parte do município de Campo Largo, conforme já citado acima, e foi fundada por iniciativa provincial. Contudo, segundo tabela em Kanashiro (2006), a Dom Pedro foi uma colônia mista, abrigando imigrantes italianos, ingleses, franceses e poloneses. Às margens do rio Passaúna ${ }^{4} \mathrm{e}$ distante a $14 \mathrm{~km}$ da área central da capital, a Colônia Dom Pedro abrigou inicialmente 23 famílias de imigrantes.

A terceira colônia de imigrantes fora de Curitiba, que merece destaque aqui é a Colônia São Mateus. Localizada no município de São Mateus do Sul, esta colônia foi demarcada pelo engenheiro agrimensor e pioneiro da imigração polonesa no Brasil Sebastião Saporski, que esteve nas terras que beiram o Rio Iguaçu para demarcar a sede da colônia, as ruas e praças, definir as divisas e comunicar ocupações territoriais indevidas ao governo. Com uma ocupação que foi inicialmente de espanhóis, os poloneses só chegaram a São Mateus ao longo da década de 1890, com a não adaptação dos primeiros ocupantes. Saporski foi administrador da colônia, e pode ser considerado seu fundador (WACHOWICZ, 2000).

\section{Vida social que se organiza e leva à introdução na política local}

Muitos estudos sobre a imigração polonesa por vezes indicam que a maioria dos indivíduos que se instalou no Paraná era de origem camponesa e empobrecida, de caráter laborioso e muito apegado à religiosidade, como é possível encontrar em Boschilia (2004), Wachowicz (1981) ou Paleczny (2000), por exemplo. Contudo isso não se confirma como uma totalidade neste grupo, pois Oliveira (2010) mostra como houve atuação de muitos imigrantes nas áreas educacional, intelectual, de imprensa e recreativa na cidade de Curitiba entre as décadas de 1890 e 1940 aproximadamente, além de figuras que se destacaram na atuação política local, também, como será apresentado aqui. Destas áreas é interessante destacar a importância central que as escolas das colônias tinham na formação das crianças imigrantes, pois o conteúdo escolar era todo lecionado em idioma polonês. Houve vários jornais em idioma

\footnotetext{
${ }^{4}$ Segundo a grafia antiga, presente em OBRZUT (2006), o rio Passaúnua era escrito: Passa-Úna.
} 
polonês que circularam em Curitiba durante este período, e o mais importante deles possivelmente tenha sido Gazeta Polska w Brazyli, que contou com a participação do pioneiro da imigração polonesa, Sebastião Saporski (WACHOWICZ, 2000). Sobre organizações sociais o destaque é para a Sociedade Junak, que organizou imigrantes e descendentes em torno de práticas esportivas e culturais durante as primeiras décadas do século XX (OLIVEIRA, 2010). Essas instituições mostram, sim, que a vida social dos imigrantes e descendentes de poloneses no âmbito urbano de Curitiba estava bastante desenvolvida e tornando-se independente da lida na terra e da rotina da colônia somente.

A década de 1940 é um marco temporal importante para as mudanças na vida social que os imigrantes e descendentes de poloneses estavam estabelecendo até então, devido às políticas nacionalizantes impostas pela ditadura $\operatorname{Vargas}^{5}$ impedindo por mais de uma década a manifestação pública de imigrantes poloneses funcionassem no país. Mesmo assim, os descendentes de poloneses tem uma presença marcante na cidade e nos bairros onde os pioneiros da imigração se instalaram, fazendo com que a região do Paraná que recebeu imigração polonesa tenha a forte presença deste grupo na sua vida cultural, com celebrações de caráter religioso e em referência à Polônia, como os ritos do catolicismo polonês, ou a benção dos alimentos na Páscoa e a festa da Padroeira da Polônia - Nossa Senhora de Chestochova no mês de agosto de todos os anos, ou também outra importante celebração, que aconteceu em junho de 2017, na cidade de Araucária, a I Polska Fest, celebração que encerrou as comemorações dos 140 anos da imigração polonesa ao município, cuja colônia polonesa mais antiga é a de Thomas Coelho, fundada em 1876 (OBRZUT, 2006). Em muitas cidades paranaenses que receberam imigração polonesa, podem-se verificar indivíduos de origem polonesa que cumpriram algum papel de relevância e destaque no desenvolvimento e modernização das cidades e do estado, durante o século XX.

Toda a repressão da ditadura Vargas não impediu que muitos imigrantes poloneses se estabelecessem em serviços públicos ou na vida pública do Paraná durante esta época, obtendo destaque na sociedade. $\mathrm{O}$ prestígio social é um conceito pertinente à sociedade de classes, que

\footnotetext{
5 A política nacionalista de Vargas afetou a comunicação, liberdade de expressão e educação em idiomas estrangeiros de diversas comunidades imigrantes no Brasil entre os anos de 1937 e 1941, aproximadamente. Com isso, Vargas pretendia integralizar imigrantes de maneira forçosa, destruir quistos regionais, e espantar o perigo das influências dos países do Eixo (Alemanha, Itália e Japão) na população brasileira. Logo, imigrantes alemães, italianos, japoneses, mas também povos de aspectos físicos e linguísticos semelhantes aos alemães - como é o caso dos poloneses - sofreram consequências bastante duras como fechamento de clubes e destruição de jornais (OLIVEIRA, 2010; SEYFERTH, 1999).
} 
emerge no Brasil e no Paraná a partir do início do século XX, e significa que a obtenção de destaque entre os demais membros da sociedade. E a distribuição de honrarias sociais se dá de acordo com as trajetórias individuais, nenhum indivíduo deve seu prestígio ao grupo de origem. É típico da sociedade de classes que o destaque social seja fruto de esforço individual e não algo conquistado por uma determinada comunidade ou um estamento social (HONNETH, 2009).

No item a seguir são apresentadas algumas trajetórias pessoais e profissionais de imigrantes e descendentes de poloneses que atuaram em pastas e cargos públicos, como secretarias ou delegacias de polícia, por exemplo, e também imigrantes que integraram os poderes legislativos e executivos dos municípios da região leste do Paraná - Curitiba e região metropolitana - além de Rio Negro e São Mateus do Sul, no sul do estado. O recorte temporal escolhido para a apresentação destes personagens é o século $\mathrm{XX}$, pois segundo os dados coletados para esta pesquisa e estudos anteriores (ROCHA, 2016) é a partir das primeiras décadas deste século que os imigrantes poloneses já se estabeleceram em suas colônias, conseguem integrar-se à vida nas cidades, criando jornais, clubes e escolas, conforme foi dito acima; trabalhando com ciência, educação, pequenas olarias e outras fábricas, entre outros ramos profissionais mais diversificados do que somente a agricultura familiar predominante nas primeiras gerações. Sendo possível, assim, analisar como e em que épocas atuaram ou atuam esses prefeitos, vereadores e funcionários públicos a fim de verificar a presença da comunidade no setor público, se é algo esparso ou mais pronunciado em uma cidade e outra, se alternam no poder com famílias tradicionais, se trazem demandas das reivindicações políticas da comunidade de descendentes, ou se legislam mais universalmente para as cidades.

\section{Imigrantes poloneses se estabelecem na política da região leste do Paraná}

Passamos agora a elencar trajetórias individuais de polono-brasileiros que alcançaram tal situação de prestígio. O primeiro personagem a ser apresentado aqui é o pioneiro da imigração polonesa ao Paraná, Sebastião Saporski.

Sebastião Edmundo Wós Saporski nasceu em janeiro de 1844, e vivia com sua família em Siolkowice na região da Silésia, que à época era pertencente à parte prussiana da Polônia, (WACHOWICZ, 2000). Partiu para a América do Sul para desertar do alistamento militar do 
Exército da Prússia, no Brasil, instala-se inicialmente em Blumenau (SC) e ao saber do interesse do governo paranaense em criar colônias para imigrantes, aposta nessa ideia e tenta a transmigração de um primeiro grupo de 16 poloneses de Blumenau para o Paraná. Era um imigrante bem relacionado com o poder local, se correspondia com o vice-governador paranaense da época - Agostinho Ermelino de Leão - de forma bastante fluida tratando sobre a transmigração de seus patrícios. Saporski foi um líder entre os imigrantes, negociava terras para abertura de novas colônias. Demarcar terras virou sua profissão, especializando-se em medições, obteve o título de agrimensor e fora nomeado pelo governo provincial para a abertura de novas colônias polonesas próximas a Curitiba, como: Santa Cândida, Tomás Coelho, Orleans, Dom Pedro, Dom Augusto, Santo Inácio, Alice e Cristina (WACHOWICZ, 2000). O bom trânsito do polonês com o governo mostra que sem ocupar cargo eletivo algum, Saporski teve uma trajetória de influência política no Paraná, carregando como pauta principal a vinda de imigrantes poloneses em situação confortável de instalação.

Outro importante personagem a ser aqui retratado, que teve influência na política local sem ter sido candidato a cargo algum foi Jerônimo Durski. O polonês naturalizado brasileiro Jerônimo Durski foi professor e fundador da primeira escola construída em uma colônia de imigrantes poloneses, em outubro de 1876 em Orleans, conforme dito anteriormente. Essa iniciativa a princípio, partira dos próprios imigrantes ${ }^{6}$ que levaram a demanda da educação aos órgãos competentes. As escolas lecionavam em idioma polonês (OLIVEIRA, 2010), até a época das políticas educacionais que visavam nacionalizar o ensino. Durski teria, segundo o autor, trabalhado em outras escolas na área urbana de Curitiba, uma delas no bairro do Batel, muito rígido, o professor lecionava aos pequenos em idioma português e em polonês.

Na prefeitura da capital e no governo do estado, é importante destacar a figura de Jaime Lerner. Nascido em Curitiba, em 1937, foi prefeito da cidade durante os anos 1970 e 1990, iniciando sua vida política com Ney Braga, inicialmente atuando no planejamento urbano da cidade e na recém-criada autarquia voltada para o tema, o IPPUC. Lerner inovou a forma de concepção urbana, criando obras marcantes na capital até os dias de hoje, como o calçadão da Rua XV de Novembro e o bairro da CIC. E governou o Paraná durante a segunda metade de 1995 a 2003, sem a característica urbanista, Lerner então implementa uma agenda neoliberal, que contou com arrocho salarial a professores e policiais e privatizações. Porém não é possível

\footnotetext{
${ }^{6} \mathrm{O}$ letramento das crianças era considerado prioridade entre os imigrantes à época da abertura das colônias, como se vê em Wachowicz (1976), sobre a inauguração da escola em Orleans.
} 
afirmar que Lerner seja um descendente de poloneses, porque, ele na verdade é um homem judeu, filho de uma família de origem polonesa. E como o grupo judaico reivindica a sua marca de forma mais contundente em seus indivíduos do que qualquer regionalidade, o grupo polonês, por sua vez, não o reconhece ${ }^{7}$ totalmente como um sendo um membro desta imigração, consideram o judaísmo como uma ressalva observada quanto ao quesito ascendência, conforme nos foi falado em entrevistas feitas com polono-brasileiros.

Sobre o poder legislativo de Curitiba, muitos representantes polono-brasileiros passaram pela Câmara Municipal desde os anos 1940, trabalhando majoritariamente em temas referentes aos imigrantes e descendentes de poloneses, entre outros assuntos. Abaixo segue a tabela com as informações referentes aos vereadores de origem polonesa em Curitiba, desde a legislatura de 1947:

Tabela 1: Vereadores de Curitiba com origem polonesa, desde a legislação de 1947.

\begin{tabular}{|c|c|c|c|}
\hline Legislatura & Nome & Partido & Informações \\
\hline $1947-1951$ & João Kracik Neto & PTB & $\begin{array}{l}\text { Nasceu em Blumenau, em 1909. Foi } \\
\text { empresário, membro do Lions Club e } \\
\text { do Country Club Graciosa. }\end{array}$ \\
\hline $1947-1951$ & $\begin{array}{l}\text { Edwino Donato } \\
\text { Tempski }\end{array}$ & UDN & $\begin{array}{c}\text { Nasceu no Rio Grande do Sul, em } \\
1913 .\end{array}$ \\
\hline 1956-1959 & $\begin{array}{l}\text { Edmundo Leining } \\
\text { Saporski }\end{array}$ & $\begin{array}{l}\text { Partido } \\
\text { Democrata } \\
\text { Cristão } \\
\end{array}$ & Nasceu em 1918. \\
\hline $\begin{array}{c}1964-1968 \text { e } \\
1973-1976\end{array}$ & Alvim Jareski & $\begin{array}{l}\text { Partido } \\
\text { Libertador }\end{array}$ & $\begin{array}{l}\text { Nasceu em Curitiba, em 1918. Foi } \\
\text { suplente de vereador nas eleições de } \\
\text { 1976, pela ARENA. }\end{array}$ \\
\hline $\begin{array}{l}1973-1976 / \\
1977-1980 / \\
1981-1982 / \\
1985-1988 / \\
1989-1992 / \\
1993-1996 / \\
1996-2000\end{array}$ & José Gorski & $\begin{array}{l}\text { Arena, PDS, } \\
\text { PDT, PTB, } \\
\text { PSB }\end{array}$ & $\begin{array}{c}\text { Vereador que mais tempo atuou na } \\
\text { Câmara, oriundo da colônia Riviera e } \\
\text { radicado no Bairro Campina do } \\
\text { Siqueira. }\end{array}$ \\
\hline
\end{tabular}

\footnotetext{
${ }^{7}$ A questão do judaísmo como marca definidora de origem ou de ascendência, ou o judaísmo como etnia, é algo muito mais complexo e que exigiria muito mais debate a respeito, algo que, no entanto, não faremos por hora. Deixando apenas claro que esta é uma fronteira existente entre o grupo estudado.
} 


\begin{tabular}{|c|c|c|c|}
\hline $\begin{array}{c}1983- \\
1988 / 1989- \\
1992 / 1993- \\
1996 / 1997- \\
2000 / 2005- \\
2008 / 2009- \\
2012 / 2013- \\
2016 / 2017- \\
2020\end{array}$ & Tito Zeglin & PTB, PDT & $\begin{array}{l}\text { Nasceu em Mandirituba, em 1954. É } \\
\text { jornalista de formação. }\end{array}$ \\
\hline $\begin{array}{c}2005- \\
2008 / 2009- \\
2012 / 2013- \\
2016 / 2017- \\
2020\end{array}$ & $\begin{array}{l}\text { Tico Kuzma } \\
\text { (Leonidas E. } \\
\text { Kuzma) }\end{array}$ & PROS & $\begin{array}{c}\text { Nasceu em Curitiba, em 1971. É } \\
\text { formado em Administração de } \\
\text { Empresas. }\end{array}$ \\
\hline $\begin{array}{l}2013- \\
2016 / 2017- \\
2020\end{array}$ & Helio Wirbiski & PPS & $\begin{array}{l}\text { Nasceu em Curitiba, no bairro do } \\
\text { Uberaba. Possui graduação em } \\
\text { Marketing e Propaganda. }\end{array}$ \\
\hline
\end{tabular}

FONTE: http://www.cmc.pr.gov.br/down/NOSSA_MEMORIA/vereadores_de_curitiba.pdf. Com complementações de ROCHA, R.M. 2015.

Dois nomes se destacam: José Gorski e Tito Zeglin. Seguem as descrições mais detalhadas sobre suas trajetórias e seus trabalhos no legislativo municipal:

\section{O Vereador José Gorski}

José Gorski nasceu em 26 de março de 1934, na colônia Riviera, em Curitiba. Foi parlamentar do município de 1973 até 2000, eleito por três partidos ideologicamente diferentes neste período. Nas eleições de 1973 e 1977, fora eleito pela Aliança Renovadora Nacional $(\text { ARENA })^{8}$. Na eleição de 1981, ele foi eleito vereador pelo PDS $^{9}$. Nas eleições seguintes, de 1985 até 1997, Gorski foi vereador pelo Partido Democrático Trabalhista (PDT) ${ }^{10}$. Gorski se afirmava como um representante da comunidade polonesa em Curitiba. Em matéria publicada em 13 de junho de 2010, o jornalista José Carlos Fernandes narra a trajetória de José Gorski em seu início na vida pública:

\footnotetext{
${ }^{8}$ A Aliança Renovadora Nacional (ARENA) surgiu em 1965 e no plano nacional, foi principal agremiação política de sustentação dos presidentes militares eleitos por via indireta, no período da ditadura civil-militar, com ideologia de direita, a ARENA existiu até 1979.

9 O PDS, Partido Democrático Social, foi uma legenda política lançada em 1980 com a proposta de ser a reorganização da Aliança Renovadora Nacional (ARENA), mantendo a ideologia direitista. O PDS existiu até 1993.

${ }^{10}$ O Partido Democrático Trabalhista (PDT) foi criado em 1979 com o propósito de reorganizar a linha política trabalhista no Brasil, tendo a flor trabalhista como símbolo, tais quais os trabalhistas internacionalmente. O PDT foi uma dissidência do Partido Trabalhista Brasileiro (PTB), cujo principal membro e fundador foi o ex-presidente Getúlio Vargas, nos anos 1940.
} 
A cada eleição, vencia no boca a boca. Apoio empresarial, só da Gráfica Elma, vizinha que imprimia as propagandas na faixa. Os filhos Ana e José Renato dobravam cartas aos eleitores e postavam. Poloneses dos quatro costados sabiam que o Gorski era gente deles. E nele votavam. (Gazeta do Povo, 13/6/2010).

Gorski também exerceu interinamente a prefeitura, entre os dias 4 e 18 de maio de 1990, segundo a mesma reportagem e documento da Câmara Municipal. Gorski apresentou projetos de lei para denominação de logradouros na capital, como as ruas Adviga Lipinski na CIC, Afonso Lipinski e Francisco Chylaszek no Orleans; também aprovou recursos para iluminação pública nas proximidades da Igreja de Santo Estanislau ${ }^{11}$, em setembro de 1999, entre muitos títulos de congratulações e Cidadão Honorário a descendentes de poloneses ilustres na cidade. Ultimamente, o Centro de Cultura Polônia Brasil está organizando o livro das memórias de Gorski, dada a sua importância para o grupo de descendentes ao qual pertence.

\section{O Vereador Tito Zeglin}

O vereador Tito Zeglin nasceu em 11 de janeiro de 1954 em Mandirituba (PR). É jornalista formado na Universidade Federal do Paraná e ocupa uma cadeira no legislativo municipal desde 1985 e segue na Câmara até o final de 2020. Neto de imigrantes poloneses que viviam em colônias em Rio Negro e Araucária, Zeglin ${ }^{12}$ se coloca como um representante da comunidade polonesa em Curitiba atualmente. Também teve projetos de lei para denominação de logradouros aprovados na Casa, e muitos outros projetos aprovados referentes a Títulos de Cidadão Honorário e Títulos de Vulto Emérito de Curitiba para descendentes de poloneses valorosos. Aprovou também, a concessão do título de Cidade Irmã de Curitiba à Varsóvia na Polônia, em dezembro de 1992. E propôs e teve aprovação, em 2005, que se instituísse o dia dois de maio de todos os anos seja declarado o Dia Municipal da Imigração Polonesa.

Há registro, também de servidores públicos de origem polonesa, no interior do estado. Segundo Relatórios de Secretários de Governo do estado do Paraná13, passaram pelas secretarias de governo, desde o início do século $\mathrm{XX}$, alguns funcionários públicos de carreira que eram descendentes de poloneses. Mostrando que o mito do imigrante camponês, não se cumpre universalmente.

Os nomes dos imigrantes ou descendentes estão aqui dispostos por ordem cronológica da nomeação e atuação no serviço público. Em 1904, na Secretaria de Negócios, Obras Públicas

\footnotetext{
${ }^{11}$ Igreja que realiza missas em polonês, localizada no centro de Curitiba.

12 Tito Zeglin ocupa a liderança do PDT (partido Democrático Trabalhista) na Câmara Municipal.

${ }^{13}$ Documentos anuais que registravam as atividades de cada pasta do governo.
} 
e Colonização o já citado imigrante polonês Edmundo Sebastião (von) ${ }^{14}$ Saporski era removido do cargo de comissário de terras da $8^{\circ}$ para a $19^{\circ}$ comissão. E Tadeus Surkoski era nomeado para retificar medição de lotes de colônias. Na mesma secretaria, em 1913 trabalharam Adão Soboczinski como inspetor de terras coloniais, e Witold Roguski, como encarregado dos estudos da estrada do Herval a Xanxerê. Soboczinski e Roguski trabalharam na mesma secretaria em que estiveram lotados alguns importantes membros da classe dominante paranaense, como os engenheiros João David Pernetta, João Moreira Garcez e Francisco Gutierrez Beltrão, o que certamente mostra um bom grau de influência destes imigrantes e também bom trânsito deles entre as classes dominantes, fazendo com que certamente, fossem vistos como postulantes à ascensão social entre seus patrícios. No ano de 1923, João Pavvlovvsky era nomeado Subdelegado do município de Paulo Frotin e Alba F. Pavvelski exercia função de professora do estado em Araucária. Na Secretaria de Fazenda trabalharam Estanislau Leminski, Feliz Ratacheski e José Sovinski, lotados na sede em Rio Negro no ano 1932. Na Secretaria de Obras Públicas Francisco Kowalski, Ladislau Kowaleski, Nicolau Rebka, João Wenceslau Ficinski Lunin eram funcionários de carreira no departamento de obras e viação, exercendo atividades com transporte de balsas pelo rio Iguaçu ou outros transportes públicos terrestres entre União da Vitória e Clevelândia e que foram nomeados no ano de 1936.

No Poder Judiciário estadual, o destaque é para alguns homens de origem polonesa que aparecem tanto como desembargadores no Tribunal de Justiça (TJ) quanto na presidência do Tribunal Regional Eleitoral (TRE). Em ordem cronológica conforme seus nascimentos seguem aqui apresentados: Segismundo Gradowski nasceu na Colônia Tomás Coelho no ano de 1897, foi nomeado desembargador do TJ em 1951. Gradowski viveu 102 anos, falecendo em 2000. Izidoro João Brzezinski nasceu em Alm. Tamandaré, em 1903, foi nomeado desembargador do TJ em 1962 e homenageado com uma rua que leva seu nome na Cidade Industrial de Curitiba, faleceu em 1990. Eros Nascimento Gradowski, nascido em Curitiba no ano de 1926. Eros era filho de Segismundo, acima citado. Foi professor da PUC-PR e das Faculdades Curitiba na área do Direito, tendo sido nomeado desembargador do TJ em 1974, faleceu em maio de 1994, Eros também tem uma rua com seu nome, no bairro Pilarzinho, em Curitiba. E por último, Zeferino Mozzato Krukoski nasceu em 1920, no distrito de Vera Guarani

\footnotetext{
${ }^{14}$ A inscrição von no nome de Saporski vem apresentada entre parênteses por dubiedade de informações. Por um lado, em documentos biográficos seus constava como o sobrenome 'Wós', que ele havia retirado de seu registro em fuga do exército prussiano, quando da vinda ao Brasil (WACHOWICZ, 2000), por outro lado no registro da secretaria em que trabalhava constava esta inscrição von. Preferimos, portanto, apresentar entre parênteses, pois não era este o principal sobrenome utilizado pelo pioneiro da imigração polonesa.
} 
em São Mateus do Sul, foi nomeado desembargador do TJ em 1973, presidiu o TRE em 1974, e em 1978 exerceu a vice-presidência do TJ-PR, faleceu em 1991.

Voltando ao Poder Executivo, há registro de que outras cidades que receberam imigração polonesa, tiveram prefeitos de origem desta imigração em sua história. A começar por Araucária, na região metropolitana, sua história política mostra que foram quatro descendentes de poloneses a ocupar a prefeitura municipal, conforme a tabela abaixo:

Tabela 2: Prefeitos de Araucária descendentes de Poloneses.

\begin{tabular}{|c|c|c|}
\hline Nome do prefeito & Época do mandato & Partido \\
\hline Francisco Trauczynski & $\begin{array}{l}\text { Novembro a dezembro de } \\
1945\end{array}$ & $\begin{array}{l}\text { Não consta a informação } \\
\text { no TRE-PR. }\end{array}$ \\
\hline $\begin{array}{l}\text { Estanislau Trauczynski } \\
\text { Sobrinho }\end{array}$ & 26/11/1946 a 06/12/1947 & PTB \\
\hline Romualdo Sobocinski & 07/12/1951 a 06/12/1955 & PTB \\
\hline Rízio Wachowicz & $\begin{array}{l}\text { Teve três mandatos entre } \\
1969 \text { e } 2000 .\end{array}$ & Arena, PPB e PFL. \\
\hline
\end{tabular}

As informações mais consistentes sobre os prefeitos de Araucária de origem polonesa dizem respeito a Rízio Wachowicz, membro da família dos professores e pesquisadores Romão e Ruy Wachowicz. Sendo que Ruy foi um notável pesquisador de historia paranaense e da história da imigração polonesa no estado, dentro da UFPR, o profesor Ry Wachowicz faleceu no ano 2000. Rízio Wachowicz foi prefeito de Araucária por três mandatos: entre 1969 e 1973, de 1977 a 1983 - ambos pela ARENA - e o último foi entre 1997 e 2000, pelo antigo PPB. Wachowicz candidatou-se novamente ao cargo de prefeito nas eleições de 2004, pelo antigo PFL, mas não foi eleito e atualmente preside em âmbito nacional a Braspol, Representação Central da Comunidade Polono- Brasileira no Brasil. 
Na prefeitura de Rio Negro, dois nomes se destacam. Alceu Antônio Swarowski, que governou a cidade por duas vezes: entre 1972 e 1976 pelo MDB, entre 1982 e 1988 pelo PMDB. Falecido em 2007, hoje em dia, Alceu Antônio Swarowski dá nome a um Centro Municipal de Educação Infantil (CMEI) em Rio Negro. E também seu filho, Alceu Ricardo Swarowski nascido em novembro de 1961, esteve à frente da prefeitura da cidade por três mandatos de 1992 a 1996, 2004 a 2008 e de 2009 até 2012, permanecendo sempre filiado so PSDB. Atualmente, Swarowski ocupa um cargo na COHAPAR. O exemplo dos nomes encontrados na cidade de Rio Negro representa uma ligeira amostra de nepotismo entre o grupo dos poloneses na política local, não é algo comum de se ver, portanto, se comparado a outros grupos da imigração, ou mesmo com as famílias da classe dominante tradicional, luso-brasileiros, em sua imensa maioria.

E, finalmente, na cidade de São Mateus do Sul, foram dois descendentes de poloneses a participarem do poder executivo, são eles: Alvin Licheski, que foi vice-prefeito entre os anos de 1976 e 1982 e Thadeo Sobocinski foi prefeito na gestão de 1968 a 1972, sendo que ambos eram membros da ARENA.

O legislativo estadual contou com vários nomes de eleitos e suplentes com origem polonesa. O primeiro a ser citado é Bronislau Ostoja Roguski ${ }^{15}$, curitibano e jornalista, Roguski foi deputado estadual entre os anos de 1947 e 1950, pela UDN. Também foi deputado federal entre 1950 e 1958. Edwino Donato Tempski ${ }^{16}$, foi deputado por dois mandatos, de 1951 a 1958 , também pela UDN. Ladislau Lachowski, um descendente de poloneses, natural de Curitiba, formado em Química pela UFPR. Lachowski foi eleito deputado estadual em 1958, e no ano seguinte ocupou cargo na Secretaria de Obras do estado. E Tadeu Sobocinski, nascido em Mallet, foi deputado pelo PSP no mandato que durou de 1951 a 1954.

\section{Considerações Finais}

A imigração polonesa no Paraná, concentrada na região leste e na capital, Curitiba foi uma das maiores em termos numéricos no estado, além do trabalho agrícola, muitos também se estabeleceram em outros setores profissionais, como na educação e jornalismo em idioma

\footnotetext{
${ }^{15}$ Segundo tabela de GOULART, 2016.

16 Tempski também foi vereador da capital, conforme mostra a tabela acima.
} 
polonês nas primeiras décadas do século XX, ou também no serviço público envolvidos com obras de demarcação, manutenção e gerenciamento de áreas coloniais, ou atuando propriamente, na vida pública. Em Curitiba, Araucária, Rio Negro e São Mateus do Sul foram localizados nomes de imigrantes e descendentes de poloneses que trabalharam no serviço público estadual, sendo funcionários de carreira, ou detentores de cargos eletivos. No caso dos vereadores em Curitiba, vê-se que legislaram para destacar e prestigiar nomes influentes no conjunto dos imigrantes.

Esta atuação ajuda a romper com a construção tão consolidada pelos historiadores da imigração polonesa que os ligava ao papel de camponeses laboriosos, católicos fervorosos e desligados do cenário urbano e moderno. Pelos perfis aqui apresentados, este não é um grupo que se destaca pela presença em partidos de esquerda, nem de tendências progressistas, posicionado-se majoritariamente no campo da direita. Por fim, este estudo é capaz de apresentar uma diferente visão sobre o cenário político no Paraná, mostrando que há presenças pontuais de descendentes que, mesmo estando aqui há quatro gerações ou menos, podem aliar-se aos grupos tradicionais em busca de espaço, ou encontrar seus espaços de poder independentemente das elites locais e exercer sua política.

\section{Referências}

BOLETIM INFORMATIVO CASA ROMÁRIO MARTINS. Santa Cândida, pioneira da Colonização Linista. Curitiba: Fundação Cultural de Curitiba. № 16. Dezembro 1975

BOSCHILIA, R. org. Reconstruindo Memórias: os poloneses do Santo Inácio. Curitiba: Universidade Tuiuti do Paraná, 2004.

GOULART, M. H. H. S. Assembleia Legislativa do Paraná: perfil parlamentar e relações de parentesco (1935-1962). 213 f. Projeto de Pesquisa relativa ao Estágio Pós-Doutoral em Sociologia, Universidade Federal do Paraná, Curitiba, 2016.

HONNETH, A. Luta por Reconhecimento. $2^{\circ}$ Edição. São Paulo: Editora 34. 2009. Parte II.

IANNI, O. As Metamorfoses do Escravo. $2^{\circ}$ Edição. São Paulo, Hecutec. Curitiba: Scientia et Labor, 1988.

KANASHIRO, M., Paisagens Étnicas em Curitiba: um olhar histórico-espacial em busca da entopia. Universidade Federal do Paraná. Cap. III. Curitiba. 2006.

OBRZUT, L. C. A Colônia Polonesa de Tomás Coelho e a Represa do Rio Passaúna - a Interface entre Tradição e Progresso. Universidade Federal do Paraná. Curitiba, 2006. 
OLIVEIRA, M. de: Organizações sociais dos Imigrantes Poloneses e seus descendentes em Curitiba (Brasil, 1890-1938). In: E/imigrações: histórias, culturas, trajetórias. LIMA, Ismênia de, HECKER Alexandre, org. $1^{\circ}$ ed. São Paulo: Expressão e Arte editora, 2010.

PALECZNY, T. Núcleos Polônicos no Brasil: Reservas de monoetnicidade ou enclaves de multiculturalismo? In: Revista Projeções - Revista de estudos polono-brasileiros. Curitiba: Editora Braspol, ano II, p. 17-38, II-2000.

ROCHA, R. M. Curitiba Polonesa?:Um estudo sobre logradouros públicos dedicados a imigrantes e descendentes de poloneses (1951-2008). Universidade Federal do Paraná, 2016.

WACHOWICZ, R.C. Orleans: Um século de Subsistência. Curitiba: Edições Paiol, 1976.

Martins, 1981. O camponês Polonês no Brasil. Curitiba: Fundação Cultural, Casa Romário 107-146, II- 2000.

: "Saporski: um pioneiro polono-brasileiro". Revista projeções, ano II, p.

BIOGRAFIA DE JAIME LERNER. Disponível em: $<$ http://www.fgv.br/cpdoc/acervo/dicionarios/verbete-biografico/lerner-jaime $>$. Acesso em 23/04/2018.

INFORMAÇÕES SOBRE OS PREFEITOS ELEITOS NAS CIDADES. Disponível em: <http://www.tre-pr.jus.br/eleicoes/resultados/resultados-de-eleicoes-municipais-tre-pr $>$. Acesso em: 07/09/2017.

INFORMAÇÕES SOBRE RÍZIO WACHOWICZ. Disponível em: <http://www.kurytyba.msz.gov.pl/pt/c/MOBILE/acontecimentos/25_anos_da_braspol>. Acesso em: 16/09/2017.

MAPA ATUAL DA CIDADE DE CURITIBA. Disponível em: 〈www.ippuc.org.br〉. Acesso em: 07/09/2017.

MAPA DA CIDADE DE CURITIBA ENTRE OS ANOS DE 1947 E 1953. Disponível em: $\langle$ http://www.museuparanaense.pr.gov.br/modules/conteudo/conteudo.php?conteudo=40 $>$. Acesso em: 16/09/2017.

RELAÇÃO DOS DESEMBARGADORES DO TJ-PR E SEUS HISTÓRICOS. Disponível em: <https://www.tjpr.jus.br/desembargadores-tjpr-museu $>$. Acesso em: 20/05/2018.

RELAÇÃO DOS PREFEITOS ELEITOS NA CIDADE DE ARAUCÁRIA. Disponível em: Fonte: 〈http://araucaria.crzdesign.com.br/node/20167>. Acesso em: 07/09/2017.

RELAÇÃO DOS PRESIDENTES DO TRE-PR. Disponível em: <http://www.tre-pr.jus.br/otre/conheca-o-tre-pr/historico>. Acesso em: 20/05/2018. 